\title{
Introdução
}

\section{Einstein e o Ano Mundial da Física}

\author{
Nelson Studart ${ }^{1}$ \\ Departamento de Física, Universidade Federal de São Carlos, São Carlos, SP, Brasil
}

O Ano Mundial da Física foi instituído para chamar a atenção do público em geral para a importância e o impacto da física no mundo contemporâneo. Proposto inicialmente por sociedades científicas de vários países, em seguida, a IUPAP (International Union of Pure and Applied Physics) adotou, por unanimidade, uma resolução apoiando a iniciativa. Finalmente, a ONU, também através de resolução, declarou 2005 o Ano Internacional da Física delegando à UNESCO a realização das atividades comemorativas. No Brasil, as atividades estão sendo organizadas pela Sociedade Brasileira de Física com o apoio do Ministério da Ciência e Tecnologia e suas agências financiadoras. Uma chamada da SBF para apresentação de propostas resultou em mais de 150 pedidos de auxílios para a realização de conferências, semanas acadêmicas, produção de materiais didáticos, exposições e ações para a melhoria dos ensinos fundamental e médio de física. São inúmeras atividades sendo desenvolvidas visando à divulgação dos temas de fronteiras da física, realçando a contribuição da física ao desenvolvimento da ciência e da tecnologia no país e debatendo o ensino da física nos vários níveis educacionais.

A escolha de 2005 coincide com o centenário da publicação dos primeiros trabalhos de Albert Einstein que revolucionaram a física. As cinco contribuições extraordinárias, que apareceram na prestigiosa revista alemã Annalen der Physik, foram a teoria da relatividade especial, a introdução do conceito de quantum de luz, a explicação do movimento browniano, a equivalência entre massa e energia e um novo método de determinação de dimensões moleculares (sua tese de doutorado). O ano de 2005 assinala ainda o cinqüentenário de sua morte e o octogésimo ano de sua passagem pelo Brasil.

Nesta edição especial, como parte das comemorações do Ano Mundial da Física, a RBEF presta homenagem ao genial físico. Coligimos oito artigos de Einstein abordando propostas originais - teoria do calor específico (1905), teoria quântica da radiação (1917), aplicação das 'regras de quantização' a sistemas integráveis multidimensionais (1917) e a 'condensação'

\footnotetext{
${ }^{1}$ E-mail: studart@df.ufscar.br.

do gás ideal (1925) -, bem como artigos preciosos de revisão e ensaios acerca de suas principais idéias, conceitos e teorias revolucionárias. Esta série de trabalhos amplia consideravelmente a obra científica de Albert Einstein em língua portuguesa complementando o conjunto dos cinco artigos recentemente editados, com textos introdutórios e comentários explicativos, no livro $O$ Ano Miraculoso de Einstein [1] e o artigo seminal sobre a relatividade geral no livro O Princípio da Relatividade [2].

A apresentação dos trabalhos de Einstein é permeada por ensaios prefaciados por físicos e historiadores. Ao final deste número especial, quatro artigos de revisão sobre cosmologia e gravitação, por pesquisadores brasileiros, são ofertados ao público leigo nestas áreas.

O historiador e especialista em estudos sobre Einstein, John Stachel, abre esta edição discutindo a situação da física por volta de 1905 e a inserção dos trabalhos de Einstein no contexto da época. Trata-se de uma versão estendida de seu artigo no suplemento especial da revista Nature 3 sobre o Ano Mundial da Física e baseia-se na palestra do autor apresentada no XVI Simpósio Nacional de Ensino de Física, realizado de 24 a 28 de Janeiro de 2005 no Rio de Janeiro. Este evento marcou oficialmente a abertura das atividades do Ano Mundial da Física no Brasil.

A seguir, Roberto Martins faz uma análise histórica dos precursores e dos resultados da dinâmica relativística, baseada na eletrodinâmica de Maxwell, antes de 1905. É interessante confrontar suas conclusões sobre a contribuição de Einstein à relatividade especial com as opiniões de outros historiadores, em particular, com a de Stachel neste número.

O historiador do Instituto Max Planck para a História da Ciência de Berlim, Jurgen Renn, discute a criação da teoria da relatividade especial procurando, em nível acessível, estabelecer de que forma os "insights teóricos de Einstein se relacionam com os outros níveis de conhecimento, em particular com aquele nível que determina nossa compreensão diária dos conceitos de tempo e espaço."

A série de trabalhos de Einstein se inicia com seu 
artigo de revisão publicado em 1907 no Jahrbuch der Radioaktivität und Elektronik. Foi escrito a convite de Johannes Stark, o fundador e editor da série. A introdução contém informação valiosa sobre a história do princípio da relatividade, referindo-se, diferentemente do artigo original, à experiência de Michelson-Morley e ao trabalho de H. Lorentz. A memória analisa com mais profundidade os princípios cinemáticos básicos e revisita a mecânica relativística. Einstein deduz de modo diferente do artigo de 1905 as transformações de Lorentz - admitindo a invariância da propagação de um pulso esférico em dois sistemas de referência inerciais (como nos livros-texto atuais). As transformações relativísticas do campo eletromagnético são derivadas e aplicadas a alguns problemas de óptica. Discute a teoria do elétron e corrige - graças a Planck - a 'anisotropia' da massa do elétron contida no artigo original 44. Apresenta ainda uma termodinâmica inspirada no trabalho de Planck do mesmo ano e promove discussões renovadas sobre os conceitos de massa e energia. Na seção 5 inicia sua longa trajetória rumo à teoria da relatividade geral, consumada em 1915, ao indagar: "É concebível que o princípio da relatividade também se aplica a sistemas que estão acelerados relativamente entre si?" De maneira heurística, elabora algumas implicações da possível relação entre o princípio da relatividade e a gravitação. Dois efeitos físicos devido ao campo gravitacional são especulados. O primeiro refere-se ao funcionamento dos relógios e das freqüências emitidas pelos átomos. O segundo diz respeito à deflexão da luz pelo campo gravitacional. Em 1911, Einstein se refere ao artigo do Jahrbuch da seguinte forma: "Há quatro anos eu procurei responder à questão da possível influência da gravidade sobre a propagação da luz. Volto agora a este tema, porque não me satisfaz a forma com que tratei o assunto e, mais ainda, porque vejo agora que uma das mais importantes conseqüências daquelas considerações pode ser submetida à verificação experimental. Refiro-me ao fato de os raios de luz que passam na proximidade do Sol sofrerem no seu campo de gravidade, segundo a teoria que se vai apresentar, um desvio tal que a distância angular entre o Sol e uma estrela fixa observada na sua proximidade é vista com um aumento aparente de quase 1 segundo de arco" 5. Este resultado motivou a organização da primeira expedição ao Brasil, mais precisamente, a Passa Quatro e Cristina em Minas Gerais, em 1912, em busca da comprovação experimental do desvio 6 .

Em A teoria de Planck da radiação e a teoria do calor específico, Einstein introduz as idéias de quantização da energia de osciladores de Planck para um sólido cristalino composto de átomos ligados entre si através de osciladores harmônicos desacoplados. Obtém, então, que o calor específico diminui com a temperatura na região de baixas temperaturas conforme indicavam resultados experimentais e em contraste com a lei de Dulong-Petit (a comparação apresentada entre os resultados teóricos e os experimentais para o diamante é notável). Pode-se afirmar que, com este trabalho, Einstein fundou a teoria quântica dos sólidos. Embora o comportamento do calor específico não correspondesse ao resultado experimental obtido pelo grupo de Walther Nernst para outros materiais, Einstein reconheceu noutro trabalho de 1911 [7] que seu modelo era bastante incipiente porque "as oscilações das moléculas estão longe de serem oscilações monocromáticas. Na verdade, um corpo comporta-se como uma mistura de ressonadores cujas freqüências próprias são distribuídas em uma determinada região". Este fato explicava por que o calor específico medido experimentalmente decai menos rapidamente para zero do que o calculado em sua teoria quântica. Explicitamente aponta que, no cálculo do calor específico, deveria ser especificada uma densidade de estados universal (não do tipo função 'delta' como fizera no artigo aqui apresentado) que "é muito difícil de determinar analiticamente" 8]. Como sabemos, Peter Debye, em 1912, conseguiu determinar com sucesso a densidade de estados correta e seu cálculo reproduziu o comportamento $T^{3}$ do calor específico dos sólidos a baixas temperaturas [9].

Por volta de 1909, Einstein começa a focalizar profundamente seu interesse para a teoria da radiação. Em carta a Jacob Laub comentou: "Estou me ocupando incessantemente com a questão da radiação e tenho mantido correspondência intensa sobre esta questão com Lorentz e Planck... Este problema quântico é tão extraordinariamente importante e difícil, de modo que todos deveriam se esforçar para trabalhar nele" 10. Em julho do mesmo ano, escreveu para Stark: "você não pode imaginar quão profundamente tenho tentado achar uma formulação matemática satisfatória da teoria quântica. Mas até agora não tenho tido sucesso" [11. Lorentz, em sua famosa palestra no congresso internacional de Roma (1908) havia sugerido que seria impossível reconciliar a fórmula de Planck para radiação do corpo negro com a teoria de Maxwell e que, portanto, a teoria dos quanta era 'mais revolucionária' do que Planck admitia [12]. Einstein, ainda funcionário do escritório de patentes em Berna, contribuiu para este debate publicando o artigo de revisão Sobre o estado presente do problema da radiação, que apresentamos nesta edição. Aqui Einstein repete os argumentos sobre a impossibilidade da teoria molecular de Maxwell-Boltzmann de explicar a radiação do corpo negro, obtendo a lei de Rayleigh-Jeans. No item 6 , deduz a famosa fórmula da mecânica estatística para as flutuações de energia $\left\langle\varepsilon^{2}>\right.$ com o objetivo de aplicá-la ao problema da radiação do corpo negro. A expressão resultante é formada por dois termos. O primeiro era "incompatível com a teoria atual...e se estivesse sozinho, forneceria uma flutuação da energia da radiação tal como se a radiação consistisse de quanta de energia $h \nu$ se movendo independentemente". Em seguida aponta que conclusões semelhantes podem ser 
obtidas calculando as oscilações da pressão da radiação devido a flutuações do momento.

Um outro ensaio notável resultou da palestra apresentada no congresso realizado em Salzburgo, em setembro de 1909, intitulada Sobre o desenvolvimento das nossas concepções sobre a natureza e a constituição da radiação. Este evento foi de suma importância para Einstein por ser a sua primeira aparição pública face a face com renomados físicos, entre eles Planck e Sommerfeld. Os temas centrais da conferência eram os problemas da radioatividade de um lado e o princípio da relatividade do outro. A estrutura da palestra é muito interessante. Einstein discute a teoria da relatividade e sua influência sobre a luz, indicando alguns fenômenos de difícil explicação de acordo com a teoria ondulatória e culminando com algumas concepções sobre a natureza da radiação. Nesta palestra que, segundo Wolfgang Pauli, pode ser vista como um dos turning points na evolução da física teórica, Einstein apresenta a sua concepção dualística da radiação prevendo que "a próxima fase do desenvolvimento da física teórica nos trará uma teoria da luz que possa ser compreendida como uma espécie de fusão da teoria ondulatória com a teoria da emissão da luz". Mas ressalta com modéstia: "Na nossa concepção sobre a estrutura da radiação, em particular da distribuição de energia no espaço irradiado, a teoria da relatividade não alterou nada. Entretanto, é minha opinião que...estamos no início de um desenvolvimento ainda não totalmente previsível, mas, sem dúvida, altamente significativo. O que eu apresentarei a seguir é, na maior parte, somente opinião pessoal, ou ainda, resultado de considerações que não foram ainda suficientemente checadas por outros. Se, apesar disso, eu as apresento aqui, isto não deve ser atribuído ao excesso de confiança nas próprias opiniões, mas sim à esperança de que um ou outro dos senhores possa se sentir motivado a interessar-se pelas perguntas em questão".

Segundo Abraham Pais, esses trabalhos de Einstein sobre a estrutura quântica da radiação não são amplamente conhecidos porque tratam de questões de princípios sem a preocupação de tirar conclusões ligadas à experiência como nos casos do efeito fotoelétrico e do calor específico dos sólidos [13].

Após a conclusão de sua teoria da relatividade geral em 1915, Einstein retoma a questão da radiação. Em 1917, publica Sobre a teoria quântica da radiação, o trabalho mais conhecido como aquele da teoria dos 'coeficientes $A$ e $B$ ', em que os conceitos de emissão espontânea e emissão estimulada são introduzidos. Neste trabalho, Einstein completa a concepção corpuscular dos quanta de luz introduzindo o momento $p=h \nu / c$ além da energia $E=h \nu$. E conclui com a seguinte observação: "energia e momento são fortemente conectados; podemos, portanto, considerar que a teoria seja justificada somente quando for demonstrado que de acordo com ela os momentos transferidos pela radiação para a matéria levem a movimentos tais como aqueles requeridos pela teoria do calor".

O renomado físico do MIT, Daniel Kleppner analisa, em detalhes, o trabalho de Einstein salientando outros conceitos fundamentais contidos no artigo que, segundo ele, é um tesouro da física.

A seguir, apresentamos um trabalho de Einstein que passou despercebido por longo tempo. Em $A$ respeito do teorema quântico de Sommerfeld e Epstein, uma generalização da regra de quantização da 'velha' teoria quântica é proposta para sistemas multidimensionais integráveis e, ao mesmo tempo, Einstein mostra que sistemas não integráveis não podem ser quantizados através desta regra. Por este trabalho, Einstein é agora reconhecido como o pioneiro da teoria do caos quântico, conforme apontado no ensaio introdutório de Marcus Aguiar.

Em setembro de 1924, Einstein inicia sua trilogia sobre a Teoria quântica do gás ideal monoatômico. No segundo tratado, o mais famoso dos três, deduziu o fenômeno da condensação de Bose-Einstein: "Sustento neste caso que um número de moléculas - com a densidade total sempre crescente - passa para o primeiro estado quântico (estado sem energia cinética) enquanto que as moléculas restantes distribuem-se de acordo com o valor do parâmetro $\lambda=1$... Uma separação surge; parte do gás 'se condensa' (o grifo é meu) e o resto permanece como um 'gás ideal saturado'. No próximo número da RBEF, Silvio Dahmen, o prefaciador e tradutor do artigo de Einstein, descreve com rigor histórico o nascimento da estatística quântica de Bose e Einstein.

A parte final deste número compreende os desenvolvimentos mais recentes e interessantes em cosmologia e gravitação escritos por proeminentes pesquisadores brasileiros. Os artigos estão escritos de modo profundo no seu conteúdo, mas acessível a uma comunidade abrangente de estudantes e especialistas em física teórica.

Este número especial não teria sido possível sem a colaboração inestimável dos tradutores, todos físicos e admiradores da obra de Einstein. É bem conhecido que Einstein escrevia com estilo apurado e com rigor linguístico. Decorre daí certa dificuldade na tradução de seus artigos e ensaios. A maioria dos textos foi traduzida diretamente do alemão e quando isso não ocorreu, uma revisão foi feita por reconhecidos conhecedores do idioma alemão. A todos eles, Carlos Alberto dos Santos, Carola Dobrigkeit Chinelatto, HansThomaz Elze, Jonas Werckmeister, Marcus A.M de Aguiar, Marta Feijó Barroso, Peter B. Schulz, Silvio Renato Dahmen e Rolando Axt, nossos sinceros agradecimentos.

Uma ajuda essencial foi dada por Vicente Pleitez, membro do Conselho Editorial da RBEF, que escolheu os temas e convidou os autores dos artigos de revisão sobre cosmologia e gravitação. Muito obrigado a Élcio Abdalla, George Matsas, Ioav Waga e Patrício Letelier 
por terem aceito nosso convite e brindado os leitores da RBEF com textos instigantes.

Ao final, agradecemos a gentileza de John Stachel, Jürgen Renn, Daniel Kleppner por concordarem com a reprodução de seus recentes trabalhos sobre Einstein e sua obra (obrigado a Penha Cardoso Dias e Silvio Dahmen pela tradução) e ao historiador da ciência, Roberto de Andrade Martins, que aceitou elaborar uma versão estendida do seu artigo, recém-publicado, sobre a dinâmica relativística antes de 1905 .

\section{Referências}

[1] J. Stachel (org.), O Ano Miraculoso de Einstein: Cinco Artigos que Mudaram a Face da Física (Editora UFRJ, Rio de Janeiro, 2001).

[2] A. Einstein, in Fundamentos da Teoria da Relatividade Geral in O Princípio da Relatividade (Fundação Calouste Gulbenkian, Lisboa, 1971), p. 141.

[3] J. Stachel, Nature 433, 215 (2005).

[4] No artigo de 1905, a definição de força usada por Einstein conduz a expressões para a massa longitudinal e massa transversal do elétron, como em outras teorias da época. Na reprodução do artigo em 1913, Einstein acrescenta uma nota: "a definição de força dada aqui não é vantajosa , tal como foi observado pela primeira vez por Planck."

[5] A. Einstein, Ann. Phys. 35, 898 (1911). Reproduzido na Ref. 2, p. 127.

[6] J. Einsenstaedt e A.A.P. Videira, in A Relatividade Geral Verificada: O Eclipse de Sobral de 29/05/1919, in Einstein e o Brasil, organizado por I.C. Moreira e A.A.P. Videira (Editora UFRJ, Rio de Janeiro, 1995), p. 77 .

[7] A. Einstein, Ann. Phys. 35, 679 (1911).

[8] A. Einstein, in Carta a W. Nernst de 20/06/1911, doc. 270, in The collected papers of Albert Einstein: The Swiss years. Correspondence 1902-1914., v. 5. (Princeton U. Press, 1995), tradução de Anna Beck.

[9] P. Debye, Ann. Phys. 39, 789 (1912).

[10] A. Einstein, Carta a J.J. Laub, doc. 160, da Ref. 8.

[11] A. Einstein, Carta a J. Stark, doc. 172, da Ref. 8.

[12] Neste contexto, T. Kuhn sustenta que o conceito de descontinuidade quântica foi criado no trabalho de Einstein de 1905, seguido de H. Lorentz e de P. Ehrenfest no período de 1906 a 1908. Ver T.S. Kuhn, Blackbody Theory and the Quantum Discontinuity, 18941912 (Oxford. U.P., Oxford, 1978).

[13] A. Pais, Sutil é o Senhor... A ciência e a vida de Albert Einstein (Nova Fronteira, Rio de Janeiro, 1995). 